\title{
Government Purchases and Real Interest Rates
}

\section{Citation}

Mankiw, N. Gregory. 1987. Government purchases and real interest rates. Journal of Political Economy 95(2): 407-419.

\section{Published Version}

http://www.journals.uchicago.edu/toc/jpe/current

\section{Permanent link}

http://nrs.harvard.edu/urn-3:HUL.InstRepos:2624457

\section{Terms of Use}

This article was downloaded from Harvard University's DASH repository, and is made available under the terms and conditions applicable to Other Posted Material, as set forth at http:// nrs.harvard.edu/urn-3:HUL.InstRepos:dash.current.terms-of-use\#LAA

\section{Share Your Story}

The Harvard community has made this article openly available.

Please share how this access benefits you. Submit a story.

\section{Accessibility}




\title{
Government Purchases and Real Interest Rates
}

\section{N. Gregory Mankiw}

Harvard University and National Bureau of Economic Research

\begin{abstract}
This paper examines the dynamic impact of government purchases in a simple general equilibrium model with both durable and nondurable consumer goods as well as productive capital. The model generates perhaps surprising results. In particular, increases in government purchases are shown to cause reductions in real interest rates. The model thus provides a possible explanation for the observed behavior of real interest rates around wars.
\end{abstract}

\section{Introduction}

The dynamic impact of fiscal policy is a central issue in macroeconomics. One outstanding puzzle regards the interaction between government purchases and real interest rates. Standard neoclassical analysis, as presented by Barro (1984), for example, implies that permanent increases in government purchases should not affect real interest rates while temporary increases in government purchases should increase real interest rates.

Data for the United States, however, provide no support for this prediction. Wars are the classic example. As Barro (1984, pp. 31516) documents, wars are not associated with high real interest rates. To the extent any systematic effect is present in U.S. data, real interest rates appear lower during wars. ${ }^{1}$

I am grateful to Andrew Abel, James Hines, Kiminori Matsuyama, Andrei Shleifer, José Scheinkman, Lawrence Summers, Laurence Weiss, Michael Whinston, and especially Paul Evans for helpful comments. This research was funded by National Science Foundation grant SES-8520044.

${ }^{1}$ Benjamin and Kochin (1984), however, report that the wars are associated with high (nominal) yields on consols in the United Kingdom for the period 1729-1931. 
In this paper I study an extension of the standard infinite-horizon neoclassical growth model and propose an explanation for this apparent anomaly. My analysis is in the spirit of much recent work that examines the dynamic effects of fiscal policy in neoclassical models (see, e.g., Hall 1980; Barro 1981; Abel and Blanchard 1983; Barro and King 1984; Judd 1985). Most previous studies, however, do not explicitly include consumer durable goods. Introducing consumer durable goods is a natural way of modifying the consumer's utility function so that it is not separable through time. ${ }^{2}$ Alternatively, one can view consumer durable goods as being another use of accumulated wealth.

I show that a simple neoclassical model incorporating a nondurable consumer good, a durable consumer good, and a durable producer good generates a perhaps surprising dynamic response to changes in government purchases. In particular, contemporaneous real interest rates and all forward rates fall in response to a permanent increase in government purchases. In response to a temporary increase in government purchases, the contemporaneous short-term rate falls while some forward rates rise.

\section{The Model}

Consider a representative consumer who is infinitely lived and has perfect foresight. He gets utility both from his current flow of the nondurable good, denoted $C$, and from the services flowing from his stock of the durable good, denoted $D$. His utility function is (with the time subscripts omitted to simplify the notation)

$$
\int_{0}^{\infty} e^{-\rho t} U(C, D) d t
$$

where $\rho(\rho>0)$ is the subjective discount rate.

Output is produced using a stock of productive capital, denoted $K$, and inelastically supplied labor, according to the production function $F(K)$. Output may be used for four purposes: consumed as a nondurable good, added to the stock of the consumer durable good, added to the stock of productive capital, or taken by the government. Since all these goods are assumed to be perfect substitutes in production, the relative prices are fixed at unity.

For simplicity, I assume that both consumer durables and productive capital depreciate exponentially at the same rate $\delta$. The goods market adding-up condition is

\footnotetext{
${ }^{2}$ For recent empirical work on durability, see Mankiw $(1982,1985)$, Dunn and Singleton (1984), Bernanke (1985), and Hayashi (1985).
} 


$$
F(K)=C+\dot{W}+\delta W+G,
$$

where

$$
W=D+K .
$$

The variable $W$ is the total stock of physical assets in the economy, and a dot denotes the derivative with respect to time; $W$ is the only state (nonjumping) variable in this economy. The division of physical assets between use by consumers $D$ and use by producers $K$ is assumed to be instantaneously reversible. While it would be plausible to add adjustment costs or nonnegativity constraints, neither feature is included here. ${ }^{3}$

To obtain the equilibrium of this economy, I solve the social planning problem. That is, I find the program that maximizes utility in (1) subject to the technological constraints (2) and (3). Government purchases are taken as exogenous.

It is straightforward to derive the first-order conditions necessary for this optimization problem. They are, together again with the constraints,

$$
\begin{gathered}
U_{C}(C, D)=\lambda, \\
U_{D}(C, D)=\lambda F^{\prime}(K), \\
W=D+K, \\
\frac{\dot{\lambda}}{\lambda}=\rho-\left[F^{\prime}(K)-\delta\right], \\
\dot{W}=F(K)-C-\delta W-G .
\end{gathered}
$$

These five equations describe how the economy will evolve given an initial wealth of the economy $W_{0}$ and the level of government purchases $G$. To interpret these five equations, it is useful to note that $r=$ $F^{\prime}(K)-\delta$ is the instantaneous real interest rate.

Equation (4) defines the costate variable $\lambda$ as the marginal utility of the nondurable good. Equation (5) states that the marginal rate of substitution between the consumer durable and the nondurable, $U_{D} / U_{C}$, equals the implicit rental price of the durable, $r+\delta$. Equation (6) again defines $W$. Equation (7) says that the growth in marginal utility depends on the real interest rate; it is the Euler equation trading off current and future nondurable consumption. Equation (8)

${ }^{3}$ In an earlier version of this paper, I examined a model without productive capital. In this alternative model, an exogenous endowment is available each period that can be consumed as a nondurable, added to the stock of the consumer durable, or taken by the government. Hence, $D$ is a state (nonjumping) variable. The impact of government purchases on real interest rates in this alternative model is very similar to their impact in the model presented here. 
states again that asset accumulation is the difference between production on the one hand and consumption, depreciation, and government purchases on the other.

\section{The Effects of Government Purchases}

This economy is most easily analyzed in terms of the state variable $W$ and the costate variable $\lambda$. Given the values of $W$ and $\lambda$, equations (4), (5), and (6) determine $C, D$, and $K$. That is, we can write

$$
\begin{aligned}
& C=C(W, \lambda), \\
& D=D(W, \lambda), \\
& K=K(W, \lambda) .
\end{aligned}
$$

The Appendix establishes with direct and tedious mathematics that if $U$ and $F$ are concave and $C$ and $D$ are normal goods, then $C_{\lambda}<0,0<$ $D_{W}<1, D_{\lambda}<0,0<K_{W}<1$, and $K_{\lambda}>0$. Using (9), (10), and (11) to solve (7) and (8) yields

$$
\frac{\dot{\lambda}}{\lambda}=\Lambda(W, \lambda)
$$

and

$$
\dot{W}=\Psi(W, \lambda)-G .
$$

The Appendix establishes that $\Lambda_{W}>0, \Lambda_{\lambda}>0$, and $\Psi_{\lambda}>0$.

\section{Steady State}

The steady-state conditions are given by equations (12) and (13) together with $\dot{\lambda}=0$ and $\dot{W}=0$. These two conditions are graphed in figure 1 . The $\dot{\lambda}=0$ locus is downward sloping, while the $\dot{W}=0$ locus has an ambiguous slope. Figure 1 is drawn with the latter locus flat; the dynamics are the same if it is upward or downward sloping. Stability requires that the $\dot{W}=0$ locus cut the $\dot{\lambda}=0$ locus from below, as in figure 1 .

Figure 1 also displays the dynamics implied by the equations of motion in each of the four regions. For any given value of the state variable $W$, the economy finds itself on the convergent path to the steady state, also shown in figure 1 .

Before I turn to the dynamic response to changes in government purchases, it is instructive to examine the differences between a high $G$ steady state and a low $G$ steady state. Since $\Psi_{\lambda}>0$, the high $G$ economy has a higher $\dot{W}=0$ locus than the low $G$ economy. The high $G$ economy therefore has a lower stock of wealth $W$ and a higher 


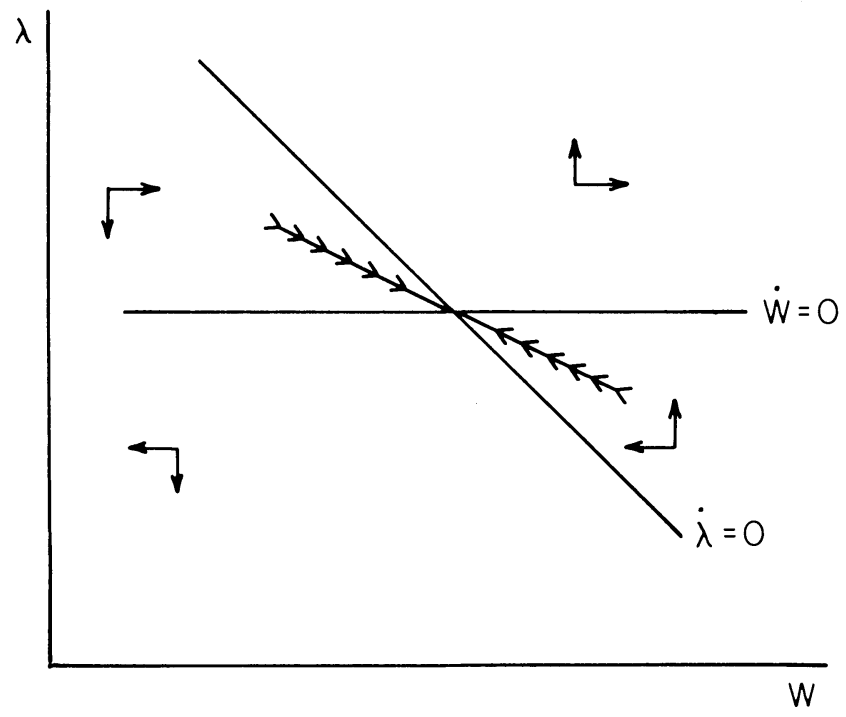

FIG. 1.-System dynamics

marginal utility of consumption $\lambda$. We see in equation (7) that the marginal product of capital, $F^{\prime}(K)$, equals $\rho+\delta$ in the steady state; hence, the stock of productive capital (and thus also the interest rate) is unaffected by the level of government purchases. The reduction in $W$ is fully borne by the stock of consumer durables. This comparison of steady states illustrates that consumer durables and producer durables are differentially affected by changes in government purchases. Intuitively, the reason is that changes in government purchases alter permanent income, which affects the desired stock of consumer durables but not the desired stock of producer durables.

\section{A Permanent Increase in Government Purchases}

Suppose the economy is at the steady-state values of $W$ and $\lambda$ for a given value of government purchases. Let us consider an increase in $G$ that is known to be permanent. Equation (13) implies that the $\dot{W}=$ 0 locus shifts upward, as shown in figure 2 . The marginal utility of the nondurable $\lambda$ immediately rises from the old steady state (point $A$ ) to the convergent path (point $B$ ). The economy then converges to the new steady state (point $C$ ), with $\lambda$ rising and $W$ falling.

What is the effect on interest rates? Remember that $r=F^{\prime}(K)-\delta$ $=\rho-(\dot{\lambda} / \lambda)$. Since $\dot{\lambda}$ is positive along the convergent path, the real interest rate falls in response to this permanent increase in government spending. As $\lambda$ approaches the new steady state, the real interest 


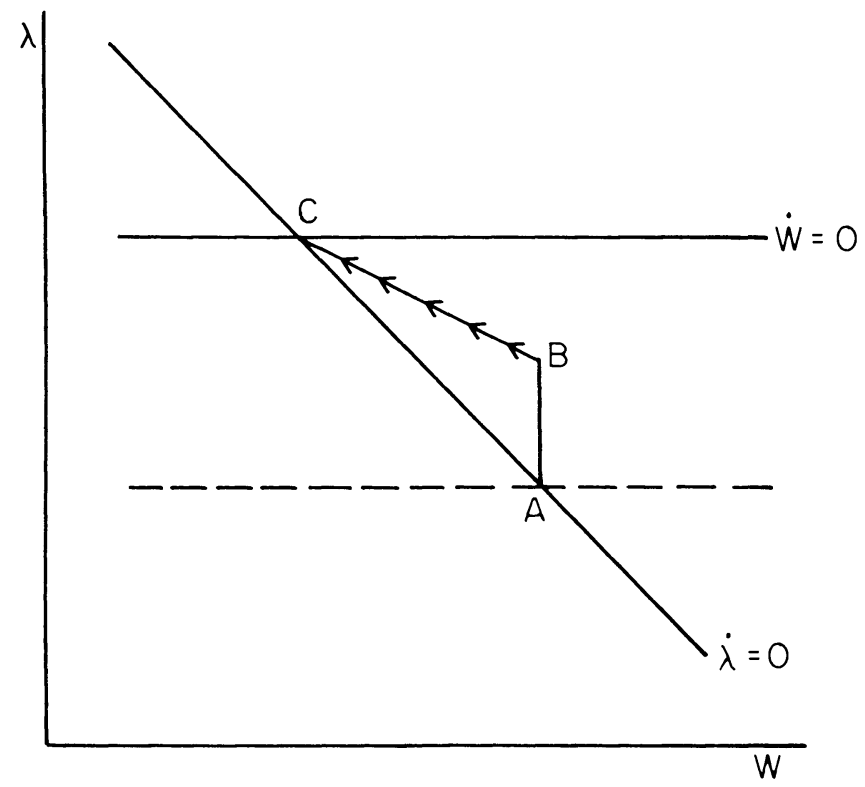

FIG. 2.-A permanent increase in government purchases

rate approaches again its steady-state value of $\rho$. The long-term interest rate, a weighted average of current and expected future shortterm rates, also falls initially when $G$ is increased, but by less than the short rate. The real yield curve is therefore upward sloping after the increase in government purchases.

The impact of government purchases on the real interest rate can also be inferred another way. Figure 2 shows that the marginal utility of consumption $\lambda$ jumps up in response to the increase in government purchases. Since $K_{\lambda}>0, K$ jumps up and $D$ jumps down. That is, some of the stock of the consumer durable is converted into productive use. Hence, the marginal product of producer capital, $F^{\prime}(K)$, falls. We see again that producer capital and consumer capital behave very differently in response to fiscal policy. Increases in government purchases crowd out capital as a whole, $W$, but temporarily crowd in producer capital at the expense of consumer capital.

The result that an increase in government purchases reduces real interest rates is perhaps surprising. The intuition behind the result is as follows. The permanent increase in government purchases causes an equal reduction in permanent income. If the interest rate remained unchanged, each consumer would attempt to adjust his consumption of the nondurable and his stock of the consumer durable to the new lower steady-state level immediately. The reduction in de- 


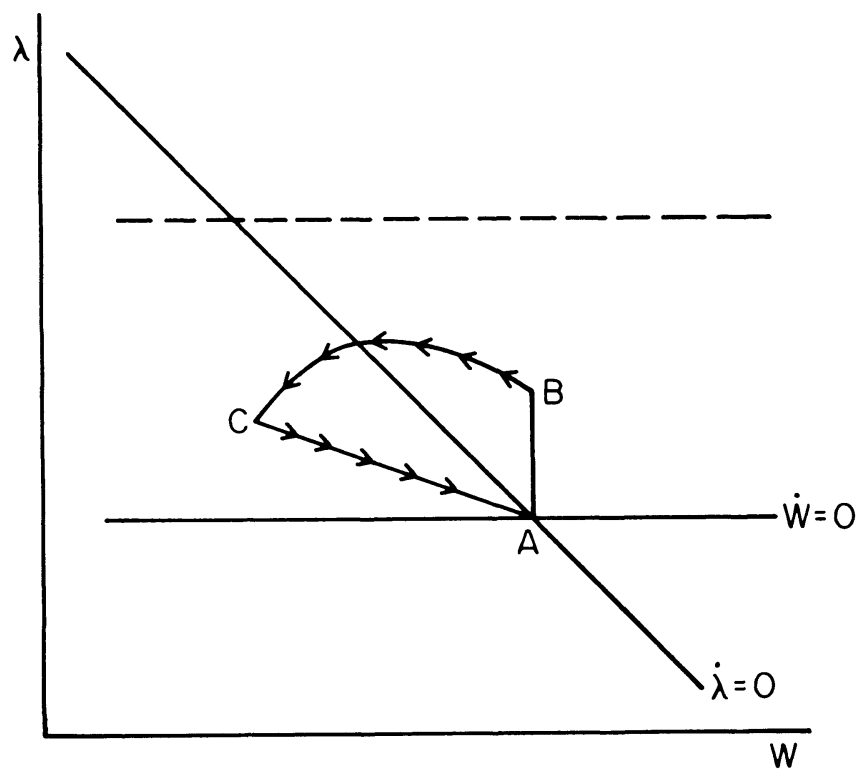

FIG. 3.-A temporary increase in government purchases

mand due to this accelerator effect on spending for consumer durables would be greater than necessary to equilibrate the goods market. The real interest rate therefore must fall to stimulate private spending.

\section{A Temporary Increase in Government Purchases}

Again suppose that the economy begins at the steady state. At time $t_{0}$ government spending increases, but the increase is known to last only until time $t_{1}$, when government spending will return to its original level.

At $t_{0}$ the $\dot{W}=0$ locus shifts upward as for a permanent increase in government spending. In choosing the dynamic path for the economy, however, one must take account of the fact that this locus will shift back to its original position at $t_{1}$. We therefore choose a path during the temporary surge in government purchases that brings us at $t_{1}$ to the path converging to the original equilibrium.

This path is shown in figure 3 . At $t_{0}$, the marginal utility of consumption $\lambda$ jumps from point $A$ to point $B$. During the period of higher government purchases, the economy travels from point $B$ to point $C$, crossing the $\dot{\lambda}=0$ locus and obeying the equations of motion for the new (high $G$ ) regime. At $t_{1}$ the $\dot{W}=0$ shifts back, the equations 
of motion change, and the economy begins returning from point $C$ to point $A$.

The pattern of the real interest rate can be gleaned from equation (7) and the time path of $\lambda$. Immediately after $t_{0}, \dot{\lambda}$ is positive, implying that the real rate is depressed by the announcement of the temporary increase in government spending. When the economy crosses the $\dot{\lambda}=$ 0 locus, $\dot{\lambda}$ becomes negative, implying that the real rate rises above $\rho$ before $t_{1}$ and remains there, gradually falling to $\rho$ as the economy returns to the steady state.

Note that the path from point $B$ to point $C$ in figure 3 is below the path converging to the high $G$ steady state. Therefore, the marginal utility of consumption $\lambda$ rises less in response to a temporary change in $G$ than to a permanent change of similar size. Since $K_{\lambda}>0$, the stock of productive capital $K$ also increases less in response to a temporary change. Because the real interest rate equals the net marginal product of capital, a temporary change in government spending has a smaller impact on the real rate than does a permanent change.

The long-term real interest rate is an average of current and future short rates. The rate on a real discount bond between two points in time can be determined by the change in marginal utility $\lambda$ between those points. Since $\lambda$ falls below its level at point $B$ at some time in the future, the return on a long-term bond over that horizon must rise when the temporary increase in government spending is announced. Remember, however, that actual long-term bonds are coupon bonds and not discount bonds. Since coupon bonds place a greater weight on more recent short rates, the rates on long-term coupon bonds rise by less and might fall.

As $t_{1}$ approaches, the long rate must rise above $\rho$. Indeed, since the long rate anticipates future short rates, the long rate will rise above $\rho$ before the short rate does. The real yield curve is downward sloping at $t_{1}$.

\section{An Announced Future Increase in Government Purchases}

Suppose the government announces at time $t_{0}$ that government purchases will permanently increase at time $t_{1}$. How does this news of future purchases affect real interest rates today?

During the period from $t_{0}$ to $t_{1}$, the laws of motion under the old (low $G$ ) regime continue to hold. The economy, however, must find itself at $t_{1}$ on the stable path converging to the new equilibrium. The dynamic path is shown in figure 4 . At $t_{0}$, marginal utility $\lambda$ jumps from point $A$ to point $B$. Before the increase in government purchases takes place, wealth $W$ is accumulated and $\lambda$ continues to rise. At $t_{1}$ the 


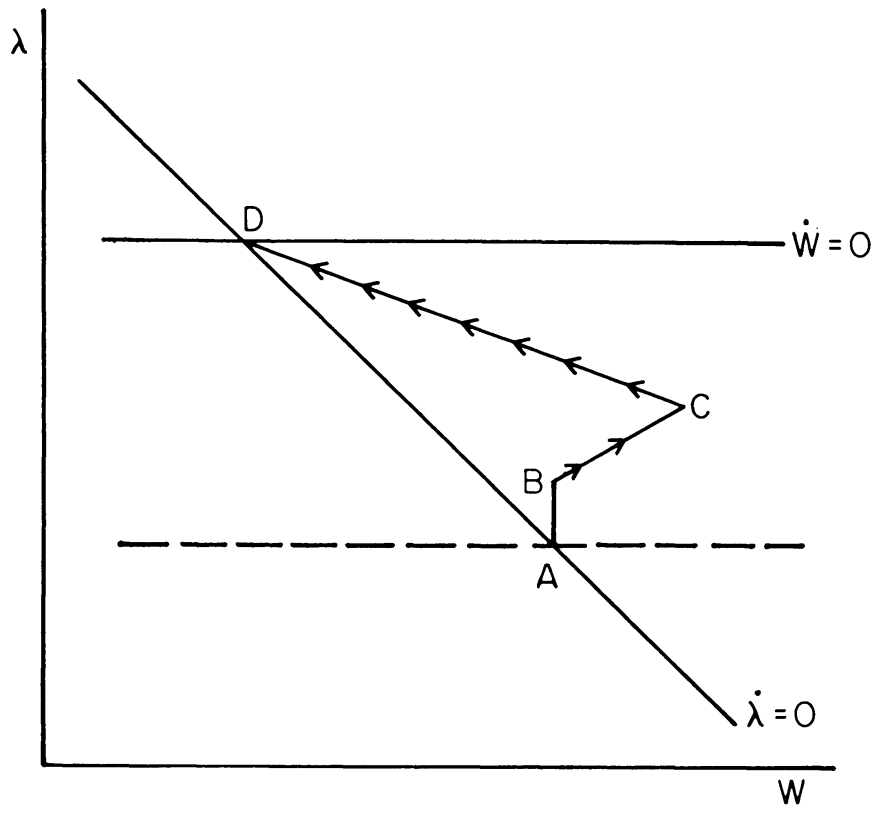

FIG. 4.-An announced future permanent increase in government purchases

economy is at point $C$, from which it converges to the new equilibrium (point $D$ ) with higher $\lambda$ and lower $W$.

The pattern of the real interest rate is again inferred from equation (7). Since $\lambda$ is rising at all times after the announcement, the instantaneous real rate is lower than $\rho$ at all times. Hence, like an immediate (permanent) increase in government purchases, an announced future increase reduces current short rates and all forward rates.

Since both $\lambda$ and $W$ are rising during the period after the announcement but before the increase in government purchases, equation (11) implies that the stock of productive capital is rising during this period. Hence, the instantaneous real interest rate is falling. After the increase takes place, the real rate converges back to the steadystate value of $\rho$. Of course, long rates anticipate this path of the short rate. The yield curve is therefore $\mathrm{V}$-shaped after the announcement; that is, intermediate-term interest rates exhibit the lowest yield to maturity.

\section{Conclusion}

I have presented a simple neoclassical model that differs from standard models by explicitly including consumer durable goods. The model generates perhaps surprising responses to changes in govern- 
ment purchases. In particular, increases in government purchases are typically associated with reductions in real interest rates.

Future research might attempt to relax some of the assumptions implicit in this model. A more realistic model might include adjustment costs, nonnegativity constraints, or time to build technology. Variable labor supply and distortionary taxation could also be introduced. Finally, if individuals had finite horizons, the way in which government purchases were financed would play a role in determining the effects of these purchases (see, e.g., Blanchard 1985).

Future research might also attempt to identify empirically the economic forces illustrated here. A variety of features of the model, however, make it clearly inappropriate for examining certain interactions between government purchases and consumer spending. First, I have implicitly assumed that government purchases do not affect the marginal utility of private consumption. More generally, public goods may be substitutes for private goods (public transportation) or complements (highways). Second, I have assumed that the changes in government purchases are exogenous. More realistically, however, there are various shocks that affect both public and private spending. For example, a positive shock to productivity makes society wealthier and thus tends to cause both public and private spending to increase. In this circumstance, it is inappropriate to attribute the change in private spending to the change in public spending. Both of these limitations suggest that the model may not be useful for examining the impact of government purchases of domestic goods. Spending on highway and school construction, for example, is likely to affect the marginal utility of private consumption and is not likely to be exogenous.

The model may be better suited for examining the impact of the government spending associated with military conflict. War expenditure may not affect the marginal utility of private consumption; moreover, wars are exogenous events, not merely reactions to technology or other shocks that might directly affect private spending. Therefore, these two limitations of the model may not be empirically important because most large movements in government purchases are associated with military conflict.

The main problem with attempting to study real interest rates around wars is that one must infer real rates from the nominal rates we directly observe. ${ }^{4}$ Since the variation in the inflation rate around

${ }^{4}$ A second problem with trying to examine the impact on real rates is that the model's implications are quite intricate. For example, real short rates should be low at the beginning of wars but high toward the end of wars. Since the duration of wars is in fact not known with certainty, it is not clear how to test this prediction. 
wartime is much greater than the variation in nominal rates, modeling expected inflation is of crucial importance. It would not be appropriate to use "rolling autoregressions" or similar models of expected inflation since the inflation process should not be expected to remain invariant between peacetime and wartime. The conventional wisdom is that wars are associated with inflation and followed by deflation. If inflation expectations reflect this conventional wisdom, the pattern of real rates tends to confirm the model.

Wars may not provide the best natural experiment, however. In contrast to standard neoclassical analysis, the model presented here implies that permanent changes in government purchases have a greater impact on real interest rates than temporary changes. The salient feature of World War II may be not the temporary surge in purchases but rather the increase that persisted past the end of the war. According to the theory of this paper, this latter change exerted a depressing effect on real interest rates of all maturities.

\section{Appendix}

This Appendix establishes the derivatives of $\Lambda$ and $\Psi$ with respect to the state variable $W$ and the costate variable $\lambda$. First, note from equations (7) and (8) that

$$
\begin{gathered}
\Lambda_{W}=-F^{\prime \prime} \frac{d K}{d W}, \\
\Lambda_{\lambda}=-F^{\prime \prime} \frac{d K}{d \lambda}, \\
\Psi_{W}=F^{\prime} \frac{d K}{d W}-\delta-\frac{d C}{d W}, \\
\Psi_{\lambda}=F^{\prime} \frac{d K}{d \lambda}-\frac{d C}{d \lambda} .
\end{gathered}
$$

Next, to obtain the derivatives in the expressions (A1)-(A4), implicitly differentiate equations (4), (5), and (6). In matrix form, the system is

$$
\left[\begin{array}{ccc}
U_{C C} & U_{C D} & 0 \\
U_{C D} & U_{D D} & -\lambda F^{\prime \prime} \\
0 & 1 & 1
\end{array}\right]\left[\begin{array}{l}
d C \\
d D \\
d K
\end{array}\right]=\left[\begin{array}{c}
d \lambda \\
F^{\prime} d \lambda \\
d W
\end{array}\right]
$$

Use Cramer's rule to solve this system. The resulting total derivatives are

$$
\begin{gathered}
\frac{d C}{d W}=\frac{-F^{\prime \prime} U_{C} U_{C D}}{\Delta}, \\
\frac{d C}{d \lambda}=\frac{U_{D D} U_{C}-U_{C D} U_{D}+\left(U_{C}\right)^{2} F^{\prime \prime}}{U_{C} \Delta},
\end{gathered}
$$




$$
\begin{gathered}
\frac{d D}{d W}=\frac{U_{C} U_{C C} F^{\prime \prime}}{\Delta}, \\
\frac{d D}{d \lambda}=\frac{U_{C C} U_{D}-U_{C D} U_{C}}{U_{C} \Delta}, \\
\frac{d K}{d W}=\frac{U_{C C} U_{D D}-\left(U_{C D}\right)^{2}}{\Delta}, \\
\frac{d K}{d \lambda}=\frac{U_{C D} U_{C}-U_{C C} U_{D}}{U_{C} \Delta},
\end{gathered}
$$

where $\Delta=U_{C C} U_{D D}-\left(U_{C D}\right)^{2}+U_{C} U_{C C} F^{\prime \prime}$. Concavity of $F$ implies that $F^{\prime \prime}<0$; concavity of $U$ implies that $U_{C C}<0, U_{D D}<0$, and $U_{C C} U_{D D}-\left(U_{C D}\right)^{2}>0$. Normality of both $C$ and $D$ implies that $U_{D D} U_{C}-U_{C D} U_{D}<0$ and $U_{C C} U_{D}-$ $U_{C D} U_{C}<0$. These assumptions imply that $\Delta>0, C_{\lambda}<0,0<D_{W}<1, D_{\lambda}<0$, $0<K_{W}<1$, and $K_{\lambda}>0$. Using (A6)-(A11) to solve (A 1)-(A4) yields

$$
\begin{gathered}
\Lambda_{W}=-F^{\prime \prime} \frac{U_{C C} U_{D D}-\left(U_{C D}\right)^{2}}{\Delta}, \\
\Lambda_{\lambda}=\frac{F^{\prime \prime}}{U_{C}} \frac{U_{C C} U_{D}-U_{C D} U_{C}}{\Delta}, \\
\Psi_{W}=F^{\prime} \frac{U_{C C} U_{D D}-\left(U_{C D}\right)^{2}}{\Delta}-\delta+\frac{U_{C D} U_{C} F^{\prime \prime}}{\Delta}, \\
\Psi_{\lambda}=\frac{-U_{C C}\left(F^{\prime}\right)^{2}-U_{D D}+2 U_{C D} F^{\prime}-U_{C} F^{\prime \prime}}{\Delta} .
\end{gathered}
$$

The assumptions of concavity and normality imply that $\Lambda_{W}>0$ and $\Lambda_{\lambda}>0$. The sum of the first three terms in the numerator of $\left(\mathrm{A}^{\prime}\right)$ is positive by the second-order conditions; hence, $\Psi_{\lambda}>0$. Without additional assumptions, $\Psi_{W}$ cannot be signed; however, its sign is not necessary for understanding the dynamics of this economy.

\section{References}

Abel, Andrew B., and Blanchard, Olivier J. "An Intertemporal Model of Saving and Investment.” Econometrica 51 (May 1983): 675-92.

Barro, Robert J. "Output Effects of Government Purchases." J.P.E. 89 (December 1981): 1086-1121.

—. Macroeconomics. New York: Wiley, 1984.

Barro, Robert J., and King, Robert G. "Time-separable Preferences and Intertemporal Substitution Models of Business Cycles." Q.J.E. 99 (November 1984): 817-39.

Benjamin, Daniel K., and Kochin, Levis A. "War, Prices, and Interest Rates: A Martial Solution to Gibson's Paradox.” In A Retrospective on the Classical Gold Standard, 1821-1931, edited by Michael D. Bordo and Anna J. Schwartz. Chicago: Univ. Chicago Press (for N.B.E.R.), 1984.

Bernanke, Ben S. "Adjustment Costs, Durables, and Aggregate Consumption." J. Monetary Econ. 15 (January 1985): 41-68. 
Blanchard, Olivier J. "Debt, Deficits, and Finite Horizons." J.P.E. 93 (April 1985): 223-47.

Dunn, Kenneth B., and Singleton, Kenneth J. "Modeling the Term Structure of Interest Rates under Nonseparable Utility and Durability of Goods." Working Paper no. 1415. Cambridge, Mass.: N.B.E.R., 1984.

Hall, Robert E. "Labor Supply and Aggregate Fluctuations." CarnegieRochester Conf. Ser. Public Policy 12 (Spring 1980): 7-33.

Hayashi, Fumio. "The Permanent Income Hypothesis and Consumption Durability: Analysis Based on Japanese Panel Data." Q.J.E. 100 (November 1985): 1083-1113.

Judd, Kenneth L. "Short-Run Analysis of Fiscal Policy in a Simple Perfect Foresight Model." J.P.E. 93 (April 1985): 298-319.

Mankiw, N. Gregory. "Hall's Consumption Hypothesis and Durable Goods." J. Monetary Econ. 10 (November 1982): 417-25.

. "Consumer Durables and the Real Interest Rate." Rev. Econ. and Statis. 67 (August 1985): 353-62. 